\title{
EVALUATION OF SPf66 MALARIA VACCINE EFFICACY IN BRAZIL
}

\author{
MARGARITA URDANETA, ALUIZIO PRATA, CLAUDIO J. STRUCHINER, C. EDUARDO TOSTA, PEDRO TAUIL, \\ AND MARCOS BOULOS \\ Escola Nacional de Saude Publica, Fundacao Oswaldo Cruz, Rio de Janeiro, Brazil; Faculdade de Medicina do Triangulo \\ Mineiro, Uberaba, Brazil; Laboratorio de Malaria, Nucleo de Medicina Tropical e Nutricao, e Departamento de Saude Coletiva, \\ Universidade de Brasilia, Brasilia, Brazil; Departamento de Doencas Infecciosas e Parasitarias, Faculdade de Medicina, \\ Universidade de Sao Paulo, Sao Paulo, Brazil
}

\begin{abstract}
This paper reports the efficacy results of the randomized, placebo-controlled, field trial of SPf66 malaria vaccine in Costa Marques, Rondonia, Brazil. This region is characterized by the seasonal distribution of Plasmodium falciparum and $P$. vivax infections, and the recent occupation by migrants from nonendemic areas. A total of 800 individuals of both sexes, ranging in age from seven to 60 years, were included in the study. Of the initial cohort, 572 participants completed the vaccination schedule. Clinical and parasitologic evaluations were obtained by active and passive searches on a periodic basis. The overall protective efficacy against $P$. falciparum infections was $-1.6 \%$ $(-32.9 \%$ to $22.4 \%)$, and $14.1 \%(-17.0 \%$ to $36.9 \%)$ for the first episode. The overall protective efficacy for $P$. vivax infections was $-19.7 \%(-44.8 \%$ to $1.03 \%)$, and $-10.8 \%(-41.1 \%$ to $12.8 \%)$ for the first episode. No statistical evidence of an overall significant protective effect of SPf66 malaria vaccine against $P$. falciparum and $P$. vivax malaria was obtained in this trial.
\end{abstract}

In the past 20 years, considerable attention and resources have been focused on the research and development of malaria vaccines. A synthetic vaccine composed of sequences of three peptides from Plasmodium falciparum merozoite and erythrocytic stages and a peptide from the circumsporozoite protein designated SPf66 has recently been tested in several populations of endemic areas in South America, Africa, and Asia. ${ }^{1-10}$ Although these studies have provided evidence that the vaccine is safe and immunogenic, the results on the efficacy are controversial, with estimates varying from $-9 \%$ to $60.2 \%$.

A randomized, placebo-controlled, field trial with the SPf66 vaccine was carried out in nonimmune residents of an endemic area in Brazil from 1991 to 1993. This is the first report of the vaccine efficacy evaluation.

\section{SUBJECTS AND METHODS}

Study area and population. The study was carried out in the municipality of Costa Marques, State of Rondonia in the Brazilian Amazon basin $\left(12^{\circ} 26^{\prime} \mathrm{S}, 64^{\circ} 14^{\prime} \mathrm{W}\right)$. The annual incidence rate of malaria has been reported to be 500 cases per 1,000 , one of the highest in the country. ${ }^{11}$ The region is characterized by the seasonal distribution of $P$. falciparum and $P$. vivax infections, and the recent occupation by migrants from nonendemic areas. Anopheles darlingi is the main local vector. Its spatial and seasonal distribution are closely related to the water levels of the local rivers and the rainy seasons. ${ }^{12-15}$

During the early stage of human colonization, the number of malaria cases increased dramatically. In 1983, a total of 3,125 cases were reported in contrast to 16,029 in 1987 , with $P$. falciparum infections being more frequent. ${ }^{16}$ Cases were observed mainly in migrants in all age groups and parasitemia was usually accompanied by classic symptoms. Subclinical infection was an exceptional finding. ${ }^{17}$ Disease control measures consisted of insecticide spraying of all houses with DDT until 1991 and with lambdacialothrim since then, as well as the treatment of cases detected by active and passive search. Since 1988, a reduction in the number of cases was observed. In 1990, 7,532 cases were reported, with $P$. vivax infections being more frequent. A preliminary survey that preceded the vaccine trial reported an overall prevalence of $10 \%$, with the ratio of $P$. falciparum to $P$. vivax infections being $1: 1 .^{18}$

Plasmodium falciparum infections are treated with a combination of quinine plus tetracycline in a 10-day schedule because resistance to chloroquine $(81.8 \%)$, sulfadoxine-pyrimethamine $(46.6 \%)$, and quinine alone $(18.2 \%)$ has been reported. ${ }^{19}$ Mefloquine is available and prescribed in cases of drug resistance that is confirmed parasitologically. Although malaria is considered to be the main health problem in the municipality, mortality is low, probably due to the easy access to diagnosis and specific treatment. ${ }^{18}$ Cases accompanied by clinical signs of possible complications such as dehydration, jaundice, and conscience alterations are referred to the main health center in the village.

The National Health Foundation (FNS) of the Brazilian Ministry of Health is responsible for conducting all control measures in the area, including treatment. According to their local records, the total population of the municipality was 23,000 inhabitants in 1991, of whom 5,975 were settlers along the main road. They constitute a very unstable group since their permanency in the area depends mainly on economic success and health conditions. Once settled, their main occupations are agriculture and lumbering. Costa Marques can be considered as an agricultural frontier, with a mesoendemic level of malaria transmission, recently colonized by nonimmune individuals. ${ }^{20}$

Vaccine. The synthetic vaccine SPf66 was developed at the Instituto de Inmunologia, Universidad Nacional de Colombia (Bogota, Colombia) by the research group of Dr. M. E. Patarroyo. ${ }^{21}$ The vaccine, as well as the placebo (tetanus toxoid for the first dose and aluminum hydroxide for the second and third doses), were bottled in clear glass vials containing 10 doses each and coded in Colombia with the letters L and S, respectively. Vaccine and placebo preparations were visually indistinguishable and were kept at $4^{\circ} \mathrm{C}$ in insulated boxes. Investigators were kept blind during the execution of the trial and until the completion of the statistical analysis. The code was broken in August 1995.

The preparations were applied in three doses: the first on 
day 0 , the second on day 30 , and the third on day 180 . The recommended dose of $0.5 \mathrm{ml}$ was applied subcutaneously in the deltoid region. ${ }^{22}$ A surveillance system for adverse reaction detection was set up during every planned vaccination. Frequency, intensity, and description of any adverse effect were systematically recorded. ${ }^{23}$

Study design and ethical considerations. The objective of this trial was to evaluate the efficacy, immunogenicity, and safety of the SPf66 vaccine in nonimmune residents of a Brazilian endemic region. With respect to vaccine efficacy, we intended to estimate the overall field direct effectiveness for all, as well as the first and second episodes of malaria infections separately for $P$. falciparum and $P$. vivax. The term field direct effectiveness applies to situations in which attempts are made to control for the unknown amount of exposure to infection in the analysis, and when indirect effects of the vaccine interact with estimates of the direct protective effect (vaccine efficacy). ${ }^{18} \mathrm{~A}$ further objective was to detect possible differences in asexual blood-stage parasite densities.

The study consisted of a randomized, double-blinded, placebo-controlled efficacy trial. The required sample size was calculated according to the World Health Organization guidelines for phase III field studies. ${ }^{24}$ We assumed a prevalence of $10 \%$ and a vaccine efficacy of $80 \%$ (as established in the first field trial $^{1}$ ). The sample size to detect such a difference at the $5 \%$ level of significance with $80 \%$ power was 134 individuals in each group. Assuming a 30\% loss to follow-up, the sample size was increased to 179 subjects. Finally, assuming a design factor of 2 , a total of 358 subjects in each treatment group seemed appropriate. We included 400 individuals in each group.

Individuals who fulfilled the selection criteria (male or female, 7-60 years of age, residing in the rural settlements along the road, and freely agreed to participate in the study) were randomly assigned a number between one and 800 . All participants with an odd number received the preparation labeled $\mathrm{L}$ and those with an even number received the preparation labeled S. The choice of this sampling method was based on its simplicity, and thus facilitated the application of the preparations without errors and allowed for the comparability between the treatment groups. All participants signed an informed consent after receiving a clear explanation of its content. The participation of children was authorized by their parents or guardians. Pregnant women and individuals with acute or severe diseases, as well as with a history of allergies, were excluded. Both the medical investigator in charge of vaccinating, as well as the recipients, were kept blind with respect to which preparation was being applied. No schizonticidal drug was administered to any of the participants before the beginning of the trial. Blood samples were collected during every scheduled vaccination and immediately examined. All participants with asexual parasitemia (either species) were adequately treated within $24 \mathrm{hr}$, according to the FNS therapeutic schemes. Participants were followed-up for 18 months after the completion of the vaccination schedule. Malaria control measures remained unchanged during the trial.

The trial was approved by the Ethical Committees of the University of Brasilia, University of Sao Paulo, and the School of Medicine of Uberaba. The study was initiate after approval from the Ministry of Health and the local authorities. Written consent was obtained from every participant.

Clinical and parasitologic follow-up. Periodic visits were scheduled on days $0,30,45,90,180,195,240,300$, $360,450,540,630$, and 720. Evaluation of spleen size was performed by palpation in the supine position on every vaccination day, and on days 540 and 720 . Blood samples were collected at every visit. Access to four FNS diagnostic and treatment stations along the road and to the village health center was available to all study participants throughout the study period, including the intervals between each scheduled visit. Microscopists in charge of the stations were responsible for registering all blood samples collected during the follow-up period. Subjects' names, identification numbers, dates, and parasitologic examination results were registered in specific notebooks.

Malaria infections were diagnosed by the microscopic examination of thick blood films prepared as recommended by the Pan American Health Organization. ${ }^{25}$ All samples were examined by the permanent staff of FNS in the field. Results were considered negative after the observation of $200 \mathrm{mi}$ croscopic fields read with a $100 \times$ oil-immersion lens and 10 eyepieces. Specific treatment was provided within $24 \mathrm{hr}$, following the detection of a positive slide. All samples were sent to the Malaria Laboratory of the Nucleo de Medicina Tropical e Nutricao, University of Brasilia, where a blind reexamination was carried out as a measure of control for reliability of results. Asexual blood-stage parasite densities were calculated by counting the number of asexual forms per 500 white blood cells and multiplying this figure by 5,500 (the average white blood cell count/ $\mu 1$ obtained for the study population), and expressed as the number of parasites $/ \mathrm{mm}^{3}$. Mortality surveillance relied on information obtained from hospital registers and/or the FNS records and from members of the community.

Capillary blood samples were collected from the study subjects during each scheduled visit. Plasma samples were sent to the reference laboratory at the University of Brasilia for the detection of IgG antibodies against asexual forms of $P$. falciparum, as well as antibodies against the vaccine peptide for evaluation of immunogenicity.

Case definition and statistical methods. A malaria case was defined as the presence of $P$. falciparum or $P$. vivax asexual blood-stage parasitemia. A new infection caused by either species was defined as a positive parasitologic examination result in a participant observed to be free of parasitemia for 30 days since a previous positive slide and adequate treatment. All positive slides between that interval were considered either as a relapse, recrudescence, and/or treatment failure.

The main analysis concerns the estimation of the field vaccine effectiveness for all, the first, and the second episodes of malaria infections detected by active and passive methods in individuals who completed the vaccination schedule. Plasmodium falciparum and $P$. vivax were considered separately. The total number of episodes (excluding possible relapses, recrudescences, and/or treatment failures), as well as total person-weeks at risk, were calculated for each participant. Total person-time was calculated by accumulating the individual length of time followed during the study period, which started 30 days after the injection of the 
third dose (induction period) and ended 1.5 years later, after subtracting 30 days for each malaria episode caused by any species. This approach was adopted after considering that asexual blood forms of $P$. vivax are sensitive to the antimalarials used for treating $P$ falciparum infections, as well as a proportion of $P$. falciparum infections being sensitive to chloroquine. Participants lost to follow-up contributed to the total person-time up to the moment when they were last observed. The overall incidence density rates for the vaccinated and placebo groups (IDv and IDp, respectively) were calculated by dividing the total number of events in each group by its corresponding person-week. The crude estimate of the overall vaccine effectiveness was determined to be 100 (1 - IDv/IDp).

The same criteria were used to calculate person-time at risk for the first episode, the follow-up ending at the event of interest (first episode) or when the study participant was last observed. The follow-up period for the second episode began four weeks after the detection of the first episode. Confidence intervals (CIs) $(95 \%)$ were calculated by the normal approximation to the log incidence density ratio (IDR $=$ IDv/IDp). Significance tests for the null hypothesis (IDR $=1$, no efficacy) were done using the normal approximation of the Mantel-Haenszel test. ${ }^{26}$ Vaccine efficacy was calculated as $\mathrm{VE}=100(1-\mathrm{IDR})$ and $95 \%$ CIs were calculated as 100(1 - IDR's CI upper limit) to 100(1 - IDR's CI lower limit). ${ }^{27} \mathrm{~A}$ similar analysis was done to estimate vaccine efficacy for the period between the second and third doses.

Further analysis was performed to explore the possible presence of heterogeneous effects of the vaccine in specific subgroups. The stratification intended to create epidemiologic categories that correlated with exposure and susceptibility of the participants to infection. The following covariates were considered: sex, age, time since arrival in the endemic region, baseline serologic titers against asexual forms of $P$. falciparum, and concomitant parasitemia (of either species) during the application of any dose of the vaccine and its induction periods. To explore the latter condition for each participant, time zero was defined as the date of detection of parasitemia plus 30 days. Stratum-specific incidence density ratios and their CIs were calculated. Survival curves were plotted according to the Kaplan-Meier approach.

\section{RESULTS}

Study population and follow-up. The present study was carried out from January 1991 to February 1993. A total of 800 volunteers $(13.4 \%$ of the total population living in the rural settlement) received the first dose of either the vaccine or placebo (400 in each group). Most of them were migrants (99.6\%), natives of nonendemic areas, and residents along the road. Both groups were comparable in relation to baseline characteristics at enrollment. ${ }^{18}$

Of the initial cohort, 714 received the second dose and 572 received the third dose (28.5\% lost to follow-up). The proportion and the average time of survival of the participants lost to follow-up up to the third dose were comparable for both treatment groups (113 vaccinees versus 115 in the placebo group; $P=0.9$, by chi-square test and 12.5 versus 11.5 weeks of survival, respectively; $P=0.5$, by Student's $t$-test). Comparability between lost participants and survivors
TABLE 1

Baseline characteristics of participants completing the vaccination schedule

\begin{tabular}{|c|c|c|c|}
\hline Characteristic & $\begin{array}{c}\text { SPf66 } \\
\text { no. }(\%)\end{array}$ & $\begin{array}{l}\text { Placebo } \\
\text { no. }(\%)\end{array}$ & $P^{*}$ \\
\hline \multicolumn{4}{|l|}{ Age (years) } \\
\hline$<11$ & $51(18)$ & $63(22)$ & \multirow[t]{4}{*}{0.45} \\
\hline $11-20$ & $93(32)$ & $96(34)$ & \\
\hline $21-50$ & $118(41)$ & $101(35)$ & \\
\hline$>50$ & $25(9)$ & $25(9)$ & \\
\hline \multicolumn{4}{|l|}{ Sex } \\
\hline Male & $177(62)$ & $171(60)$ & \multirow[t]{2}{*}{0.68} \\
\hline Female & $110(38)$ & $114(40)$ & \\
\hline \multicolumn{4}{|c|}{ Time since arrival (years) } \\
\hline$<1$ & $111(39)$ & $111(39)$ & \multirow[t]{4}{*}{0.95} \\
\hline $1-2$ & $54(19)$ & $56(20)$ & \\
\hline$>2-3$ & $46(16)$ & $48(17)$ & \\
\hline$>3$ & $76(26)$ & $70(24)$ & \\
\hline \multicolumn{4}{|c|}{ Previous malaria episodes } \\
\hline None & $24(8)$ & $35(12)$ & \multirow[t]{3}{*}{0.30} \\
\hline $1-3$ & $72(25)$ & $67(24)$ & \\
\hline Several & $191(67)$ & $183(64)$ & \\
\hline \multicolumn{4}{|c|}{ IgG antibodies to Plasmodium falciparum } \\
\hline Positive & $89(31)$ & $81(28)$ & \multirow[t]{2}{*}{0.49} \\
\hline Negative & $198(69)$ & $204(72)$ & \\
\hline \multicolumn{4}{|l|}{ Spleen } \\
\hline Palpable & $71(26)$ & $70(26)$ & \multirow[t]{2}{*}{0.99} \\
\hline Unpalpable & $207(74)$ & $204(74)$ & \\
\hline \multicolumn{4}{|c|}{ Prevalence of infection at enrollment } \\
\hline P. falciparum & $9(2)$ & $9(2)$ & \multirow[t]{3}{*}{0.63} \\
\hline$P$. vivax & $16(4)$ & $11(3)$ & \\
\hline Negative & 367 (94) & $370(95)$ & \\
\hline
\end{tabular}

was maintained with respect to all characteristics, and losses seemed to be independent of the disease and of secondary reactions to the vaccine or placebo. The main causes of losses were absence of the participants (117) and/or the presence of any acute disease during the scheduled vaccination (38), and emigration from the study area (36). Deaths (2) were not related to malaria or the vaccine/placebo preparations. Losses were evenly distributed between both groups and the randomization effect was not compromised. ${ }^{18}$

Both groups were considered comparable with respect to the baseline characteristics at the moment of application of the third dose (Table 1). Although comparability was achieved, the study population was heterogeneous within each group in relation to age, sex, and previous contact with malaria infection, indicating a heterogeneous exposure to the source of infection and susceptibility to it.

Adverse effects. No severe adverse reactions were detected with either dose of application or in any group. Local reactions such as mild inflammation, nodules, and pain or erythema, frequently accompanied by pruritus, were the most common reactions detected in both groups $(3.8 \%$, $29.1 \%$, and $8.5 \%$ for the first, second, and third doses, respectively, in the SPf66 group, and $4.0 \%, 7.6 \%$, and $2.5 \%$ in the placebo group), and were significantly higher in vaccinees after the application of the second and third doses $(P$ $<0.0001$ and $P<0.0035$, respectively, by chi-square test). Local side effects after the second dose were more frequent in females in the vaccinated group $(P<0.0001$, by chisquare test). Systemic side effects consisted mainly of unspecific general symptoms reported by the participants, and 
TABLE 2

Stratum-specific vaccine efficacy estimates for the first Plasmodium falciparum malaria episode after the third dose

\begin{tabular}{|c|c|c|c|c|c|c|c|}
\hline \multirow[b]{2}{*}{ Stratum } & \multicolumn{3}{|c|}{ SPf66 } & \multicolumn{3}{|c|}{ Placebo } & \multirow{2}{*}{$\begin{array}{l}\mathrm{VE}(\%) \\
(95 \% \mathrm{CI}) \dagger\end{array}$} \\
\hline & No. of cases & Person-weeks & IDv* & No. of cases & Person-weeks & IDp* & \\
\hline Crude & 76 & 12,178 & 0.0062 & 85 & 11,698 & 0.0073 & $\begin{array}{c}14.11 \\
(-17.0-36.9)\end{array}$ \\
\hline \multicolumn{8}{|l|}{ Sex } \\
\hline Males & 48 & 7,273 & 0.0066 & 44 & 7,196 & 0.0061 & $\begin{array}{c}-7.94 \\
(-62.5-28.3)\end{array}$ \\
\hline Females & 28 & 4,905 & 0.0057 & 41 & 4,503 & 0.0091 & $\begin{array}{c}37.30 \\
(-1.4-61.2)\end{array}$ \\
\hline \multicolumn{8}{|l|}{ Age (years) } \\
\hline$<11$ & 12 & 2,404 & 0.0049 & 19 & 2,861 & 0.0066 & $\begin{array}{c}24.8 \\
(-54.9-63.5)\end{array}$ \\
\hline $11-20$ & 27 & 3,628 & 0.0074 & 21 & 4,034 & 0.0052 & $\begin{array}{c}-43.0 \\
(-152.9-19.16)\end{array}$ \\
\hline $21-50$ & 34 & 4,985 & 0.0068 & 38 & 3,599 & 0.0106 & $\begin{array}{c}35.39 \\
(-2.6-59.32)\end{array}$ \\
\hline$>50$ & 3 & 1,162 & 0.0026 & 7 & 1,203 & 0.0058 & $\begin{array}{c}55.63 \\
(-71.6-88.53)\end{array}$ \\
\hline \multicolumn{8}{|c|}{ Time since arrival (years) } \\
\hline$<1$ & 36 & 4,408 & 0.0089 & 40 & 3,913 & 0.0102 & $\begin{array}{c}13.0 \\
(-36.5-44.5)\end{array}$ \\
\hline $1-2$ & 17 & 2,227 & 0.0076 & 14 & 2,271 & 0.0062 & $\begin{array}{c}-23.9 \\
(-151.3-38.9)\end{array}$ \\
\hline$>2-3$ & 9 & 2,239 & 0.0040 & 16 & 2,233 & 0.0072 & $\begin{array}{c}43.91 \\
(-26.9-75.2)\end{array}$ \\
\hline$>3$ & 14 & 3,664 & 0.0038 & 15 & 3,280 & 0.0046 & $\begin{array}{c}16.44 \\
(-73.1-59.7)\end{array}$ \\
\hline \multicolumn{8}{|c|}{ IgG antibodies to Plasmodium falciparum } \\
\hline Negative & 55 & 8,302 & 0.0066 & 58 & 8,453 & 0.0069 & $\begin{array}{c}3.45 \\
(-39.6-33.2)\end{array}$ \\
\hline Positive & 19 & 3,632 & 0.0052 & 24 & 3,229 & 0.0074 & $\begin{array}{c}29.62 \\
(-28.5-61.45)\end{array}$ \\
\hline \multicolumn{8}{|c|}{ Intercurrent malaria in vaccine applications } \\
\hline P. falciparum & 13 & 1,653 & 0.0079 & 17 & 1,594 & 0.0107 & $\begin{array}{c}26.24 \\
(-51.9-64.2)\end{array}$ \\
\hline$P$. vivax & 28 & 2,743 & 0.0102 & 20 & 2,678 & 0.0075 & $\begin{array}{c}-36.7 \\
(-142.6-23.0)\end{array}$ \\
\hline None & 35 & 7,783 & 0.0045 & 48 & 7,426 & 0.0065 & $\begin{array}{c}30.42 \\
(-7.6-55.0)\end{array}$ \\
\hline
\end{tabular}

* IDv and IDp $=$ incidence density rates in the vaccinated and placebo groups.

$\dagger \mathrm{VE}(\%)=$ vaccine efficacy estimates; $\mathrm{CI}=$ confidence interval.

were most frequent after the first dose in both groups $(4.3 \%$ in the SPf66 group and $3.0 \%$ in the placebo group). ${ }^{23}$

Passive and active case detection. After the third dose, 5,684 blood samples were collected either by the active $(3,427)$ or passive $(2,257)$ surveillance systems, 2,891 in the vaccinees and 2,793 in the placebo group. A total of 967 positive slides were detected, 520 in the vaccine group (179 corresponding to $P$. falciparum infections and 341 to $P$. vivax), and 447 in the placebo group (175 P. falciparum and 272 P. vivax). Excluding relapses and/or treatment failures, 212 P. falciparum infections were confirmed, 107 in 76 participants in the vaccine group, 24 through the active periodical searches, and 83 through the FNS surveillance system, and 105 episodes were detected in 85 participants in the placebo group, 23 through the active periodical searches, and 82 through the FNS surveillance system. A total of 427 $P$. vivax infections were detected, 233 in 138 participants in the vaccine group and 194 in 127 participants in the placebo group.

Protective effectiveness for $\boldsymbol{P}$. falciparum malaria episodes. The crude estimate of the overall direct vaccine effectiveness was $-1.6 \%(-32.4 \%$ to $22.4 \%)$ and $14.1 \%$
$(-17.0 \%$ to $36.9 \%)$ for the first episode. For the second episode, the estimate was $-50.9 \%(-172.7 \%$ to $16.4 \%)$. Although not significant, marked differences in point estimates of vaccine efficacy for the first episode can be observed in all subgroups, especially those related to sex, age, and the presence of concomitant parasitemia with either species during application of any dose of the vaccine during its induction periods (Table 2). In the subgroup of participants free of intercurrent malaria during vaccine applications, the overall protective effect was $17.2 \%(-19.9 \%$ to $42.8 \%)$, and $30.4 \%(-7.6 \%$ to $55.0 \%)$ for the first episode. The stratified analysis for the first episode showed closer estimates of vaccine efficacy between females and males, but differences in age subgroups were marked. Adults more than 20 years of age showed a significant level of protection (Table 3). Vaccine efficacy for the second episode was $-27.3 \%(-171.9 \%$ to $40.4 \%$ ). The frequency distribution of all $P$. falciparum malaria episodes and total person-weeks at risk for participants completing the vaccination schedule and Kaplan-Meier survival curves for the first episode under both analytical approaches are presented in Table 4 and Figure 1, respec- 
TABLE 3

Stratum-specific vaccine efficacy estimates for the first Plasmodium falciparum malaria episode after the third dose in participants free of intercurrent parasitemia during vaccine applications and/or induction periods

\begin{tabular}{|c|c|c|c|c|c|c|c|}
\hline \multirow[b]{2}{*}{ Stratum } & \multicolumn{3}{|c|}{ SPf66 } & \multicolumn{3}{|c|}{ Placebo } & \multirow{2}{*}{$\begin{array}{l}\mathrm{VE}(\%) \\
(95 \% \mathrm{CI}) \dagger\end{array}$} \\
\hline & No. of cases & Person-weeks & IDv* & No. of cases & Person-weeks & IDp* & \\
\hline Crude & 35 & 7,783 & 0.0045 & 48 & 7,426 & 0.0065 & $\begin{array}{c}30.42 \\
(-7.6-55.0)\end{array}$ \\
\hline \multicolumn{8}{|l|}{ Sex } \\
\hline Males & 21 & 4,669 & 0.0045 & 28 & 4,634 & 0.0060 & $\begin{array}{c}25.57 \\
(-31.1-57.7)\end{array}$ \\
\hline Females & 14 & 3,113 & 0.0045 & 20 & 2,792 & 0.0072 & $\begin{array}{c}37.22 \\
(-24.3-68.3)\end{array}$ \\
\hline \multicolumn{8}{|l|}{ Age (years) } \\
\hline$<11$ & 9 & 1,508 & 0.0059 & 11 & 1,995 & 0.0055 & $\begin{array}{c}-8.2 \\
(-161.1-55.2)\end{array}$ \\
\hline $11-20$ & 13 & 2,088 & 0.0062 & 10 & 2,336 & 0.0043 & $\begin{array}{c}-45.4 \\
(-231.6-36.2)\end{array}$ \\
\hline $21-50$ & 13 & 3,348 & 0.0039 & 21 & 2,444 & 0.0086 & $\begin{array}{c}54.8 \\
(9.7-77.4)\end{array}$ \\
\hline$>50$ & 0 & 837 & 0 & 6 & 651 & 0.0092 & Undefined \\
\hline \multicolumn{8}{|c|}{ Time since arrival (years) } \\
\hline$<1$ & 18 & 2,136 & 0.0084 & 23 & 2,563 & 0.0089 & $\begin{array}{c}-6.1 \\
(-73.9-49.3)\end{array}$ \\
\hline $1-2$ & 5 & 1,302 & 0.0038 & 6 & 1,214 & 0.0049 & $\begin{array}{c}22.3 \\
(-154.5-76.3)\end{array}$ \\
\hline$>2-3$ & 6 & 1,805 & 0.0033 & 10 & 1,481 & 0.0068 & $\begin{array}{c}50.78 \\
(-35.4-82.1)\end{array}$ \\
\hline$>3$ & 6 & 2,439 & 0.0024 & 9 & 2,169 & 0.0041 & $\begin{array}{c}43.05 \\
(-60.0-79.7)\end{array}$ \\
\hline \multicolumn{8}{|c|}{ IgG antibodies to Plasmodium falciparum } \\
\hline Negative & 28 & 5,622 & 0.0049 & 35 & 5,508 & 0.0063 & $\begin{array}{c}21.62 \\
(-20.8-52.32)\end{array}$ \\
\hline Positive & 7 & 1,941 & 0.0036 & 12 & 1,911 & 0.0063 & $\begin{array}{c}42.56 \\
(-4.59-77.4)\end{array}$ \\
\hline
\end{tabular}

* IDv and IDp $=$ incidence density rates in the vaccinated and placebo groups.

$\dagger \mathrm{VE}(\%)=$ vaccine efficacy estimates; $\mathrm{CI}=$ confidence interval.

tively. No differences in the mean parasite densities between the two groups were found.

The crude protective effect for the first episode after the second dose was $-20.4 \%(-86.1 \%$ to $22.0 \%)$. In the participants free of concomitant parasitemia during the first and/or second doses and their induction periods, the field vaccine effectiveness was $-0.6 \%$ ( $-82.9 \%$ to $44.6 \%)$.
Protective effectiveness for $\boldsymbol{P}$. vivax malaria episodes. The frequency distribution of all $P$ vivax malaria episodes and total person-weeks at risk are presented in Table 5. The overall vaccine effectiveness was $-19.7 \%(-44.8 \%$ to $1.03 \%)$ and $-10.8 \%(-41.1 \%$ to $12.8 \%)$ for the first episode. In the subgroup of participants free of concomitant parasitemia during the injection of either vaccine dose and

TABLE 4

Frequency distribution and vaccine efficacy estimates for Plasmodium falciparum malaria episodes in participants who completed the vaccination schedule*

\begin{tabular}{|c|c|c|c|c|}
\hline & \multicolumn{4}{|c|}{ Analytical approach } \\
\hline & \multicolumn{2}{|r|}{ All participants } & \multicolumn{2}{|c|}{$\begin{array}{l}\text { In participants free of intercurrent } \\
\text { parasitemia during vaccine applications }\end{array}$} \\
\hline & $\begin{array}{c}\text { SPf66 } \\
(\mathrm{n}=269)\end{array}$ & $\begin{array}{l}\text { Placebo } \\
(\mathrm{n}=271)\end{array}$ & $\begin{array}{c}\text { SPf66 } \\
(\mathrm{n}=159)\end{array}$ & $\begin{array}{l}\text { Placebo } \\
(\mathrm{n}=165)\end{array}$ \\
\hline \multicolumn{5}{|l|}{ Number of episodes } \\
\hline 0 & 193 & 186 & 124 & 117 \\
\hline 1 & 53 & 65 & 23 & 34 \\
\hline 2 & 16 & 20 & 8 & 14 \\
\hline 3 & 6 & 0 & 4 & 0 \\
\hline 4 & 1 & 0 & 0 & 0 \\
\hline Total no. of events & 107 & 105 & 51 & 62 \\
\hline Person-weeks & 14,844 & 14,799 & 9,152 & 9,216 \\
\hline Incidence rate & 0.0072 & 0.0071 & 0.0055 & 0.0067 \\
\hline \multicolumn{5}{|l|}{ Vaccine efficacy } \\
\hline Overall (CI) & \multicolumn{2}{|c|}{$-1.6 \% \quad(-32.9 \%$ to $22.4 \%)$} & \multicolumn{2}{|c|}{$17.2 \% \quad(-19.9 \%$ to $42.8 \%)$} \\
\hline First episode $(\mathrm{CI})$ & \multicolumn{2}{|c|}{$14.11 \%(-17.0 \%$ to $36.97 \%)$} & \multirow{2}{*}{\multicolumn{2}{|c|}{$\begin{array}{l}30.42 \%(-7.6 \% \text { to } 55.0 \%) \\
-27.3 \% \quad(-171.9 \% \text { to } 40.43 \%)\end{array}$}} \\
\hline Second episode (CI) & $-50.9 \%$ & $(-172.7 \%$ to $16.48 \%)$ & & \\
\hline
\end{tabular}

\footnotetext{
$* \mathrm{CI}=$ confidence interval.
} 


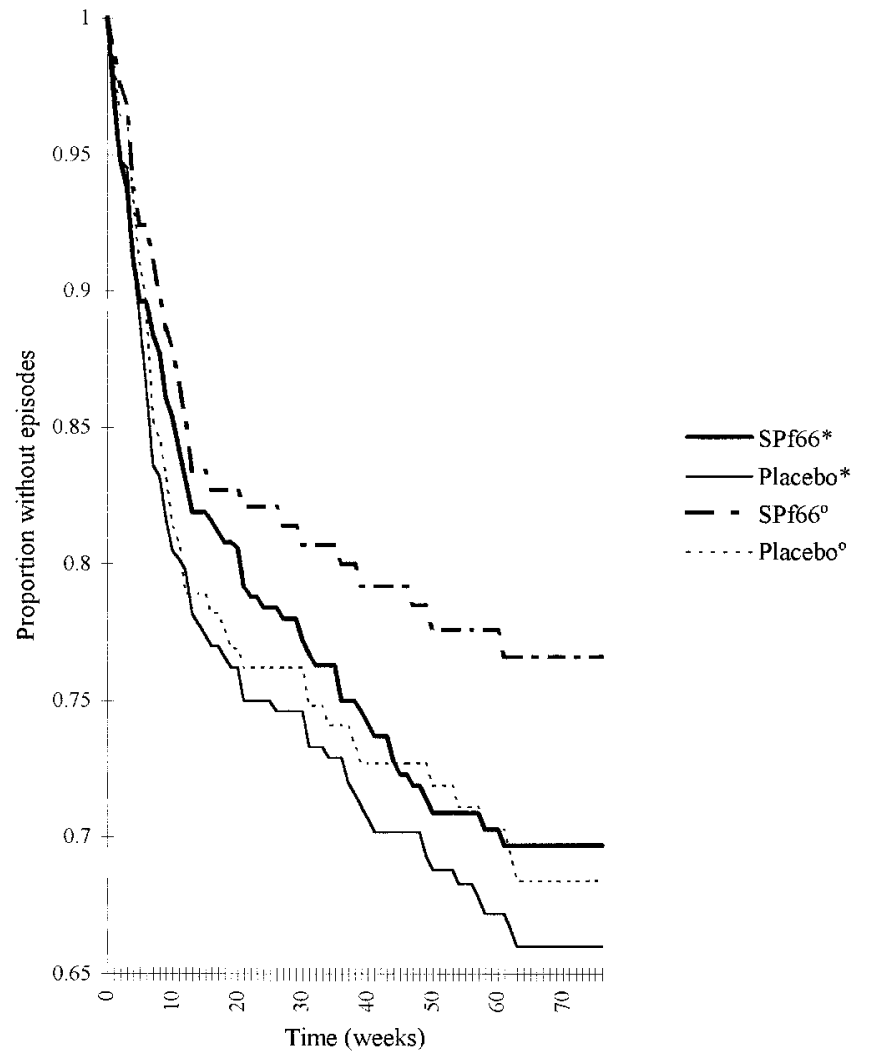

FIGURE 1. Kaplan-Meier survival curves for the first $P$. falciparum malaria episode after the third dose of SPf66 vaccine. *All participants; ${ }^{\circ}$ Participants without intercurrent parasitemia during vaccine applications. its induction periods, the overall estimate was $-13.4 \%$ $(-47.9 \%$ to $13.0 \%)$ and $-12.3 \%(-55.0 \%$ to $18.6 \%)$ for the first episode.

\section{DISCUSSION}

No evidence of an overall significant protective effect of SPf66 malaria vaccine against $P$. falciparum and $P$. vivax malaria episodes were obtained in this trial. Caution is advised regarding the interpretation of the results given the small sample size, which was calculated to detect an overestimated $80 \%$ vaccine efficacy, and a significant amount of losses to follow-up, both resulting in lack of precision of the estimates as reflected in wide confidence intervals.

Three special conditions characterized this trial: 1) the participants were mainly migrants with low, if any, acquired immunity; 2) in the study area, $P$. vivax and $P$. falciparum infections coexist, and the population has easy access to diagnosis and specific treatment; and 3) no radical treatment was administered to the participants before the scheduled vaccinations. These facts raise important issues for discussion.

Migrants were natives of different regions of Brazil, representing a variety of ethnic groups, probably with distinct genetic features. There is increasing evidence that immune response to SPf66 might be genetically restricted. ${ }^{28-31}$ Immunogenicity is being evaluated and we intend to clarify this point in the future.

Coexistence of both $P$. falciparum and $P$. vivax infections in the study area raises important points. First, several criteria can be used to define distinct infections and persontime at risk, with a resulting modification of vaccine efficacy estimates. Second, the use of antimalarials is widespread in the area, and it is not clear how the rapid clearance of parasitemia might affect the expected natural boosting of the immune response in vaccinated individuals. However, no ev-

TABLE 5

Frequency distribution and vaccine efficacy estimates for Plasmodium vivax malaria episodes in participants who completed the vaccination schedule*

\begin{tabular}{|c|c|c|c|c|}
\hline & \multicolumn{4}{|c|}{ Analytical approach } \\
\hline & \multicolumn{2}{|r|}{ All participants } & \multicolumn{2}{|c|}{$\begin{array}{l}\text { In participants free of intercurrent } \\
\text { parasitemia during vaccine applications }\end{array}$} \\
\hline & $\begin{array}{c}\text { SPf66 } \\
(\mathrm{n}=269)\end{array}$ & $\begin{array}{l}\text { Placebo } \\
(\mathrm{n}=271)\end{array}$ & $\begin{array}{c}\text { SPf66 } \\
(\mathrm{n}=159)\end{array}$ & $\begin{array}{l}\text { Placebo } \\
(\mathrm{n}=165)\end{array}$ \\
\hline \multicolumn{5}{|l|}{ Number of episodes } \\
\hline 0 & 131 & 144 & 82 & 95 \\
\hline 1 & 75 & 80 & 45 & 45 \\
\hline 2 & 42 & 34 & 26 & 20 \\
\hline 3 & 14 & 8 & 5 & 3 \\
\hline 4 & 6 & 3 & 1 & 1 \\
\hline 5 & 0 & 2 & 0 & 1 \\
\hline 6 & 0 & 0 & 0 & 0 \\
\hline 7 & 0 & 0 & 0 & 0 \\
\hline 8 & 1 & 0 & 0 & 0 \\
\hline Total no. of events & 233 & 194 & 116 & 103 \\
\hline Person-weeks & 14,844 & 14,799 & 9,152 & 9,216 \\
\hline Incidence rate & 0.0157 & 0.013 & 0.0126 & 0.0117 \\
\hline \multicolumn{5}{|l|}{ Vaccine efficacy } \\
\hline Overall (CI) & \multicolumn{2}{|c|}{$-19.74 \%(-44.86 \%$ to $1.03 \%)$} & \multicolumn{2}{|c|}{$-13.4 \%(-47.9 \%$ to $13.02 \%)$} \\
\hline First episode (CI) & \multicolumn{2}{|c|}{$-10.8 \% \quad(-41.12 \%$ to $12.86 \%)$} & \multicolumn{2}{|c|}{$-12.3 \%(-55.0 \%$ to $18.66 \%)$} \\
\hline Second episode (CI) & $-34.0 \%$ & $(-91.87 \%$ to $8.13 \%)$ & -23.0 & $27.11 \%)$ \\
\hline
\end{tabular}

$* \mathrm{CI}=$ confidence intervals. 
idence of an increased protection was observed for the second episode. On the contrary, estimated vaccine effectiveness was negative, suggesting that previous infections do not boost protection.

An increased incidence of $P$. vivax episodes was observed among vaccinated individuals. This may have led to an overestimation of the vaccine efficacy against $P$ falciparum infections since vaccinees would have received a greater number of doses of chloroquine as compared with the placebo group and approximately $18 \%$ of $P$. falciparum infections are considered to be sensitive to chloroquine. Although $P$. vivax infections are not associated with mortality, they are an important cause of morbidity and economic losses. A potential increase in the number of cases caused by this species following vaccination with SPf66 would also increase the burden on traditional control measures.

Since no radical treatment was administered to the participants before the scheduled vaccinations, information on the effect of intercurrent parasitemia during vaccine applications was explored. Point estimates suggest that concomitant parasitemia during either dose of vaccination and/or during the induction periods can possibly affect the protective effect of the vaccine, probably due to the immunosuppression effect associated with acute malaria. Vaccine efficacy estimates among individuals free of concomitant parasitemia during vaccine injections seem closer to the concept of biological efficacy of the vaccine against $P$. falciparum malaria episodes. No evidence of protection against the first episode of $P$. falciparum malaria was observed except among individuals more than 20 years of age. Age-related differences in vaccine efficacy estimates may reflect different levels of exposure to infection and susceptibility patterns.

Phase III field trials of SPf66 have been carried out in very heterogeneous conditions throughout the world. Studies in South America were conducted in Colombia, Venezuela, and Ecuador in areas of low endemicity and in all age groups except infants. Vaccine efficacy estimates were $33.6 \%$ (CI $=18.8-45.7 \%), 55 \%(\mathrm{CI}=21-75 \%)$, and $60.2 \%(\mathrm{CI}=$ $-26 \%$ to $88 \%$ ), respectively. ${ }^{3-5}$ A vaccine efficacy estimate of $-9 \%(\mathrm{CI}=-33 \%$ to $14 \%)$ in children $2-15$ years of age was obtained in Thailand in area of low-to-medium endemicity. ${ }^{9}$ Plasmodium falciparum and $P$. vivax malaria infections coexist in all of these areas. In spite of the similarities in these endemic areas, different case definitions and methods for handling $P$. vivax concomitant episodes were used. In addition, radical treatment before each programmed vaccination was provided only in Thailand. The comparison of our observations to these trials, particularly those conducted in South America, should consider additional information not available to us on how intercurrent malaria parasitemia during the vaccine applications and/or induction periods were handled in the analysis, as well as how person-time at risk was defined in case of $P$. vivax infections.

The trials in Africa were conducted in Tanzania and The Gambia, both areas of high endemicity, yet one with intense perennial malaria transmission and the other with seasonal transmission. ${ }^{6,8}$ Treatment with sulfadoxine-pyrimethamine was provided before vaccination to all participants in both trials and $P$. falciparum malaria infections predominated. The vaccine efficacy estimates obtained in these trials differed markedly. An estimated protective effect of $31 \%$ (CI
$=0-52 \%$ ) was obtained in Tanzanian children 2-5 years of age in contrast with a vaccine efficacy estimate in Gambian infants 6-11 months of age of $8 \%$ ( $\mathrm{CI}=-18 \%$ to $29 \%$ ).

When one considers that the vaccine is to be a public health tool, we cannot base our conclusions on its efficacy against the first episode, but on its overall efficacy. Overall protective efficacies of SPf66 malaria vaccine against $P$. falciparum infections were estimated in the Colombian trial (38.8\%) but the CI was not reported. ${ }^{3}$ More recently, a protective efficacy of $25 \%$ ( $\mathrm{CI}=1-44 \%$ ) was reported for the Tanzanian trial. ${ }^{10}$ Estimated overall protective efficacies for other field trials range from $3 \%$ to $66.8 \%$ (Gambia and Ecuador, respectively), but none are statistically significant. ${ }^{4,8}$

Results obtained in the several field trials to date can be formally pooled together with meta-analytic techniques. In addition to an increase in power, one could also benefit from the heterogeneous conditions in which these trials were conducted to understand the role of previous infection with malaria in modulating the immune response to the vaccine. Such procedures must take into account possible differences in immune response related to age, as well as the role of intercurrent malaria infections, on the protective effect of the vaccine.

Acknowledgments: We are grateful to Dr. M. E. Patarroyo and his research group for providing SPf66 vaccine, and to the volunteers from Costa Marques, the local health agents of the FNS, and local authorities for unconditional help. Special thanks are given to Dr. Agostinho Cruz Marques (FNS-Brasilia) for logistic and operational support, and to Pedro de Souza, Francisco das Chagas Oliveira Luz, Harley Azevedo Jr., Airton Medeiros Dias, and Shigueru Ofugi for executing the laboratory procedures.

Financial support: The Brazilian trial was funded by the Ministry of Health, National Health Foundation (FNS) of Brazil, the Pan American Health Organization, and the Brazilian National Research Council (CNPq).

Authors' addresses: Margarita Urdaneta and Claudio J. Struchiner, Escola Nacional de Saude Publica, Fundacao Oswaldo Cruz, Rua Leopoldo Bulhoes 1480, Manguinhos, Rio de Janeiro, RJ, CEP: 21041-210, Brazil. Aluizio Prata, Medicina Tropical, Faculdade de Medicina do Triangulo Mineiro, Caixa Postal: 118, Uberaba, Minas Gerais, MG, CEP: 38001-970, Brazil. C. Eduardo Tosta: Laboratorio de Malaria, Nucleo de Medicina Tropical e Nutricao, Universidade de Brasilia, Brasilia, DF, CEP: 70910-900, Brazil. Pedro Tauil, Departamento de Saude Coletiva, Universidade de Brasilia, Brasilia, DF, CEP: 70910-900, Brazil. Marcos Boulos, Instituto de Medicina Tropical, Departamento de Doencas Infecciosas e Parasitarias, Faculdade de Medicina, Universidade de Sao Paulo, Av. Eneias Carvalho de Aguiar 470, Sao Paulo, SP, CEP: 05403-000, Brazil.

Reprint requests: Aluizio Prata, Faculdade de Medicina do Triangulo Mineiro, Medicina Tropical, Caixa Postal: 118, Uberaba, CEP: 38001-970, Minas Gerais, Brazil.

\section{REFERENCES}

1. Amador R, Moreno A, Valero V, Murillo L, Mora AL, Rojas M, Rocha C, Salcedo M, Guzman Espejo F, Nunez F, Patarroyo ME, 1992. The first field trials of the chemically synthesized malaria vaccine SPf66: safety, immunogenicity and protectivity. Vaccine 10: 179-184.

2. Amador R, Moreno A, Murillo LA, Sierra O, Saavedra D, Rojas M, Mora AL, Rocha CL, Alvarado F, Falla JC, Orozco M, Coronell C, Ortega N, Molano A, Velaquez JF, Valero MV, Franco L, Guzman F, Salazar LM, Espejo F, Mora E, Farfan R, Zapata N, Rosas J, Calvo JC, Castro J, Quinones T, Nunez F, Patarroyo ME, 1992. Safety and immunogenicity of the 
synthetic malaria vaccine SPf66 in a large field trial. J Infect Dis 166: 139-144.

3. Valero MV, Amador LR, Galindo C, Figueroa J, Bello MS, Murillo LA, Mora AL, Patarroyo G, Rocha CL, Rojas M, Aponte JJ, Sarmiento LE, Lazada DM, Coronell CG, Ortega NM, Rosas JE, Alonso PL, Patarroyo ME, 1993. Vaccination with SPf66, a chemically synthesized vaccine, against Plasmodium falciparum malaria in Colombia. Lancet 341: 705-710.

4. Sempertegui F, Estrella B, Moscoso J, Piedrahita L, Hernandez D, Gaybor J, Naranjo P, Mancero O, Arias S, Bernal R, Cordova ME, Suarez J, Zicker F, 1994. Safety, immunogenicity and protective effect of the SPf66 malaria synthetic vaccine against Plasmodium falciparum infection in a randomized double-blind placebo controlled field trial in an endemic area of Ecuador. Vaccine 12: 337-342.

5. Noya O, Gabaldon Y, Alarcon de Noya B, Borges R, Zerpa N, Urbaez JD, Madonna A, Garrido E, Jimenez MA, Borges RE, Garcia P, Reyes I, Prieto W, Colmenares C, Pabon R, Barraez T, de Caceres LG, Godoy N, Sifontes R, 1994. A populationbased clinical trial with the SPf66 synthetic Plasmodium falciparum malaria vaccine in Venezuela. J Infect Dis 170: $396-$ 402.

6. Alonso PL, Smith T, Armstrong Schellenberg JRM, Masanja H, Mwankusye S, Urassa H, Bastos de Azevedo I, Chongela J, Kobero S, Menendez C, Hurt N, Thomas MC, Lyimo E, Weiss NA, Hayes R, Kitua AY, Lopez MC, Kllama WL, Teuscher T, Tanner M, 1994. Randomised trial of efficacy of SPf66 vaccine against Plasmodium falciparum malaria in children in southern Tanzania. Lancet 344: 1175-1181.

7. Teuscher T, Armstrong Schellenberg JRM, Bastos de Azevedo I, Hurt N, Smith T. Hayes R, Masanja H, Silva Y, Lopez MC, Kitua A, Kilama W, Tanner M, Alonso PL, 1994. SPf66, a chemically synthesized subunit malaria vaccine, is safe and immunogenic in Tanzanians exposed to intense malaria transmission. Vaccine 12: 328-336.

8. D'Alessandro U, Leach A, Drakely CJ, Bennett S, Olaleye B, Fegan GW, Jawara M, Langeroc P, George MO, Targett GAT, Greenwood BM, 1995. Efficacy trial of malaria vaccine SPf66 in Gambian infants. Lancet 346: 462-467.

9. Nosten F, Luxemburger C, Kyle DE, Ballow WR, Wittes J, Wah E, Chongsuphajaisiddhi T, Gordon DM, White NJ, Sadoff JC, Heppner DG, 1996. Randomized double-blind placebo-controlled trial of SPf66 malaria vaccine in children in northwestern Thailand. Lancet 348: 701-707.

10. Alonso PL, Smith TA, Armstrong-Schellenberg JRM, Kitua AY, Masanja H, Hayes R, Hurt N, Font F, Menendez C, Kilama WL, Tanner M, 1996. Duration of protection and age-dependence of the effects of the SPf66 malaria vaccine in African children exposed to intense transmission of Plasmodium falciparum. J Infect Dis 174: 367-372.

11. World Health Organization, 1994. World malaria situation in 1992. Wkly Epidemiol Rec 43: 317-321.

12. Klein TA, Lima JBP, 1990. Seasonal distribution and biting patterns of Anopheles mosquitoes in Costa Marques, Rondonia, Brazil. J Am Mosq Control Assoc 6: 700-706.

13. Klein TA, Lima JBP, Tada MS, 1991. Comparative susceptibility of anopheline mosquitoes in Rondonia, Brazil to infection by Plasmodium vivax. Am J Trop Med Hyg 45: 463-470.

14. Klein TA, Lima JBP, Tada MS, 1991. Comparative susceptibility of anopheline mosquitoes to Plasmodium falciparum in Rondonia, Brazil. Am J Trop Med Hyg 44: 598-603.

15. Klein TA, Lima JBP, Tang AT, 1991. Biting behavior of Anoph- eles mosquitoes in Costa Marques, Rondonia, Brazil. Rev Soc Bras Med Trop 24: 13-20.

16. McGreevy PB, Dietze R, Prata A, Hembree SC, 1989. Effects of immigration on the prevalence of malaria in rural areas of the Amazon Basin of Brazil. Mem Inst Oswaldo Cruz 84: 485-491.

17. Prata A, Urdaneta M, McGreevy PB, Shugiro Tada M, 1988. Infrequency of asymptomatic malaria in an endemic area in Amazonas, Brazil. Rev Soc Bras Med Trop 21: 51-54.

18. Urdaneta M, Prata A, Struchiner CJ, Tosta CE, Tauil P, Boulos M, 1996. SPf66 vaccine trial in Brazil: conceptual framework study design and analytical approach. Rev Bras Med Trop 29: 259-269.

19. Prata A, 1992. A eficacia das atuais medidas de controle da malaria: drogas antimalaricas. Rev Soc Bras Med Trop 25 (suppl II): 37-40.

20. World Health Organization, 1988. Report on a Technical Consultation on Research and Support of Malaria Control in the Amazon Basin. Brasilia: World Health Organization, TDR/FIELDMAL/SC/AMAZ/88.

21. Moreno A, Patarroyo ME, 1989. Development of an asexual blood stage malaria vaccine. Blood 74: 537-546.

22. Rocha CL, Murillo LA, Mora AL, Rojas M, Franco L, Cote J, Valero MV, Moreno A, Amador R, Nunez F, Coronell C, Patarroyo ME, 1992. Determination of the immunization schedule for field trials with the synthetic malaria vaccine SPf66. Parasite Immunol 14: 95-109.

23. Urdaneta M, Prata A, Struchiner CJ, Tosta CE, Tauil P, Boulos M, 1996. Safety evaluation of SPf66 malaria vaccine in Brazil. Rev Soc Bras Med Trop 29: 497-501.

24. World Health Organization, 1989. Guidelines for the Evaluation of Plasmodium falciparum Asexual Blood-Stage Vaccines in Populations Exposed to Natural Infection. Geneva: WHO, TDR/MAP/AVE/89.

25. Lopez-Antunano FJ, Schmunis G, 1988. Diagnostico de Malaria. Publicacao Cientifica, No. 512. Washinton, DC: Pan Amercian Health Organization.

26. Kleinbaum DG, Kupper LL, Morgenstein H, 1982. Epidemiologic Research Principles and Quantitative Methods. Belmont, CA: Lifetime Learning Publications.

27. Smith PG, Morrow RH, 1992. Methods for Field Trials of Interventions Against Tropical Diseases. New York: Oxford University Press, 293.

28. Patarroyo ME, Vinasco J, Amador R, Espejo F, Silva Y, Moreno A, Rojas M, Mora AL, Salcedo M, Valero V, Goldberg AK, Kalil J, 1991. Genetic control of the immune response to a synthetic vaccine against Plasmodium falciparum. Parasite Immunol 13: 509-516.

29. Murillo LA, Rocha CL, Mora AL, Kalil J, Goldenberg AC, Patarroyo ME, 1991. Molecular analysis of HLA DR4- $\beta 1$ gene in malaria vaccinees: typing and subtyping by PCR technique and oligonucleotides. Parasite Immunol 13: 201-210.

30. Murillo LA, Tenjo FA, Clavijo OP, Orozco MA, Sampaio S, Kalil J, Patarroyo ME, 1992. A specific T-cell receptor genotype preference in the immune response to a synthetic Plasmodium falciparum malaria vaccine. Parasite Immunol 14: 87-94.

31. Beck H-P, Felger I, Barker M, Bugawan T, Genton B, Alexander N, Jazwinska E, Erlich H, Alpers M, 1995. Evidence of HLA class II association with antibody response against the malaria vaccine SPf66 in a natural exposed population. Am J Trop Med Hyg 53: 284-288. 